\title{
Dynamic Relationship between Urbanization, Energy Consumption and Environmental Degradation in Pakistan: Evidence from Structure Break Testing
}

\author{
Arshian Sharif * $\quad$ Syed Ali Raza ${ }^{\dagger}$
}

\begin{abstract}
This study investigates the Carbon dioxide emission-urbanization-growth nexus in Pakistan by taking time series data from the period of 1972 to 2013. The study applied three approaches of co-integration (ARDL bounds test, Johansen and Juselius and Gregory and Hansen structural break test) to confirm the valid long-run positive interaction between carbon dioxide emission and urbanization. The robustness of cointegrating vectors are further checked using FMOLS and DOLS tests and the results validate the long-run coefficients. The results of VDM exhibit the uni-directional causality between carbon dioxide emission and urbanization running from urbanization to carbon dioxide emission. It was therefore noted that policies in which the government needs to allocate greater portion to environmental safeguard and energy saving components in the planning, such as encouraging energy saving framework and creating a chain of increasing indicators of environmental protection and energy saving.
\end{abstract}

Keywords: Urbanization, energy consumption, carbon dioxide emission, Pakistan.

\section{Introduction}

Urbanization is a process of shifting of population from rural regions to urban regions and the mode in which society adapts to the change, but it is not limited of transferring people from rural to urban areas. It also the progression of the fundamental conversion of rural regions into urban regions, in short urbanization is the occurrence of social and economic innovation. Urbanization has marked a milestone in year 2010, in that year world urbanization has reached to $50 \%^{1}$. Now a day's world has experienced quick urbanization in the last four decades. From the year 1975 to 2007, the world urban population has improved from 1.52 billion to 3.29 billion (United Nations, 2008). However, urbanization increased and continues to increase in developed countries and in developing countries is predictable to increase. Moreover, urban population is predicted to twice to about 6.4 billion by the end of 2050. This perhaps causes additional resource consumption, put further pressure on the already delicate economic system. Cities spent around $2 / 3$ of

\footnotetext{
*Department of Management Sciences, Iqra University, Karachi-75300, Pakistan.

E-mail: arshian.aslam@gmail.com

${ }^{\dagger}$ Corresponding author. Othman Yeop Abdullah Graduate School of Business, Universiti Utara Malaysia, 06010 UUM Sintok, Kedah Darul Aman, Malaysia. E-mail: syed_aliraza@hotmail.com

${ }^{1}$ Data sourced from http://esa.un.org/unup/.
} 
global energy then formed above $70 \%$ of worldwide carbon dioxide emission (CE), still half of the population lived in urban regions (International Energy Agency, 2008).

In recent years, the association between numerous environmental issues, containing energy consumption and emission with urbanization has been discussed widely. Various researchers indicate that urbanization increases the demand of energy, which producing further emissions (Jones, 1991; Parikh \& Shukla, 1995; Cole \& Neumayer, 2004; York, 2007). Contrariwise, former researchers claimed that urbanization decreases energy demand by utilizing their public infrastructure (e.g. Utilities and public conveyance) efficiently, which reduce and condense energy consumption and its emissions (Newman \& Kenworthy, 1989; Liddle, 2004; Chen, Jia, \& Lau, 2008).

Earlier investigation revealed a very mixed effect, signifying that the relationship between energy consumption, energy emission and urbanization is complex. Most of the previous researches have indirectly presumed that the relationship and effect of urbanization on energy expenditure and energy emission is consistent for whole republics, but this cannot be possible because various characteristic variances between countries of diverse levels of wealth. It also contradicts by urban environmental transition theories that at different level of development, urbanization pressure can diverge on the environment. MacKellar, Lutz, Prinz, and Goujon (1995); Shi (2003) found the greater effect of population development on energy usage and emission in developed and developing countries. Nevertheless, there is still an ambiguity whether the influence of urbanization on Carbon dioxide productions and consumption of energy fluctuates through the different level of income or development. Further research with extensive consideration will be beneficial for the government and policy makers.

Urbanization is continuously increasing in Pakistan since 1970s. In Pakistan the trend of Urbanization is shown in Table-1. In 1970's the urban population was 15.85 million. This urban population was steady but constantly improved in 1980's, 1990's and in 2000's to $22.45,33.97$ and 47.69 respectively. In the last three years, urbanization performance, increasing slowly from 2011 to 2013 of annual urban population of $65.20,67.06$ and 68.96. There are various causes that explain the increasing level of urban population in Pakistan. First of all, there is a rapid increase in the employment opportunity in urban areas that's why people start shifting from rural regions to urban regions and continuously improving urbanization since 1970s.

Table 1

Trend of Urbanization, Energy Consumption and Carbon Emissions in Pakistan

\begin{tabular}{lccc}
\hline Time Period & $\begin{array}{c}\text { Urbanization } \\
\text { (Millions) }\end{array}$ & $\begin{array}{c}\text { Energy Consumption } \\
\text { (Million Tons) }\end{array}$ & $\begin{array}{c}\text { Carbon Emissions } \\
\text { (Million Tons) }\end{array}$ \\
\hline $1970 \mathrm{~s}$ & 15.85 & 7.99 & 20.04 \\
$1980 \mathrm{~s}$ & 22.45 & 14.27 & 33.54 \\
$1990 \mathrm{~s}$ & 33.97 & 27.77 & 66.98 \\
$2000 \mathrm{~s}$ & 47.69 & 44.33 & 111.10 \\
2011 & 65.20 & 68.34 & 165.84 \\
2012 & 67.06 & 69.17 & 167.27 \\
2013 & 68.96 & 69.61 & 168.71 \\
\hline \multicolumn{2}{l}{ Source: World Bank, British Petroleum }
\end{tabular}

In comparison with other developing countries, Pakistan has a high consumption and 
emission of energy. In Pakistan movement and trend of energy consumption and emission are shown in Table-1. The regular annual value of energy consumption and emission were 7.99 and 20.04 million in 1970s. In Pakistan the energy consumption and emission are increasing improved by $79 \%$ and $67 \%$, In 1980s the average annual value of energy consumption and emission were 14.27 and 33.54 million respectively. Moreover, in Pakistan the energy consumption and emission sharply improved and with an average value of 27.77 and 66.98 million during 1990s. In Pakistan the situation of energy consumption and emission have better and the values are increased by significantly 95 and 99 percent in 1990s. The average annual value of energy consumption and emission were 44.33 and 111.10 million in 2000's. However, the energy consumption and emission in Pakistan are increasing from last three years, which was 2011 to 2013 with a value of $68.34,69.17$ and $69.61,165.84,167.27$ and 168.71 respectively.

The prime purpose of this research is to identify the effect of urbanization on energy consumption and CE. This study includes a time series data of Pakistan from 1972 to 2013, the outcomes will explain the control of urbanization on energy consumption and CE. This unique empirical results pursue the attention of policy maker and also make a significant contribution to the existing literature.

The rest of the study is ordered as follows. Section 2 demonstrates the empirical studies covered on urbanization with energy consumption or emission. Section 3 discusses the detailed empirical model and framework while, Section 4 explain and describe the consequences. Lastly, Section 5 suggests the brief conclusion and effective policy implications.

\section{Review of Related Literature}

The relationship of urbanization and numerous practices of environmental density, such as consumption of energy and CE, has been widely explored in the past eras. In a cross section data framework Jones (1991) examined the bonding among urbanization and energy consumption and its emission, results suggested that a progressive correlation exists between urban and energy per capita, urbanization increased the transport energy and energy usage per unit of production. Ehrhardt-Martinez, Crenshaw, and Jenkins (2002) explain the correlation between urbanization and deforestation rate by using the environmental Kuznet curve model (EKC). The result explained that deforestation rate increase in the starting age of urbanization, then depreciate when urbanization spreads. York, Rosa, and Dietz (2003a, 2003b) also established a positive effect of urbanization on energy consumption and its emission via STIRPAT model.

In a time series data background S. Alam, Fatima, and Butt (2007) examined the influence of urbanization on energy emission and found a positive association among urbanization and energy emission. Similarly Holtedahl and Joutz (2004); Liu (2009) also found the positive impact of urbanization on the usage of energy, but the amount of influencing is decreased by the improvement in technological and industrial infrastructure and more effective and efficient utilization of available resources.

In panel data perspective, Newman and Kenworthy (1989) explored the association between urban density and energy use in transport by using panel data of 32 cities in 
high income countries, and created that increase in urban density causes decrease in per capita transport energy use. Parikh and Shukla (1995) explained that urbanization help to increase consumption of energy in three different ways. First, by increasing energy consumption through the demands of good and services. Second, by transferring energy usage from traditional fuels to modern fuels and third, through straight household and transport consumption. Dhakal, Kaneko, and Imura (2002) found the per capita CE was lesser in high development cities like (Tokyo and Seoul) than low development cities like (Beijing and Shanghai). Liddle (2004) argued that the relationship concerning urbanization and population density is adverse by using EKC model in OECD countries, suggesting that populated and highly urbanized countries have less demand for private transport. Pachauri (2004) explained that per capita energy consumption (household) is higher in urban areas of India as compared to the rural areas. But, when regulating the effect of household size and household spending, urban citizens had a lower energy requirement than rural citizens. York (2007) established the relationship between urbanization and energy by using STIRPAT model and concluded that in most modernized countries, urbanization also improve the usage of energy. Pachauri and Jiang (2008) also got the same evidence and explain some reason for difference among urban and rural household energy usage.

The first reason is that the population lives in rural areas are continuing dependent on ineffective fuels (coal and charcoal). Second the population lives in urban areas depend on more efficient modern fuel (petroleum gas and electricity). Chen et al. (2008) scrutinize the impact of urban density and per capita energy consumption (household) and concluded that a negative link exists between them. Mishra, Smyth, and Sharma (2009) described that the association between urbanization and energy per capita was positive in French Polynesia, Fiji, Samoa and Tonga, but negative in New Caledonia. Dodman (2009) investigated the per capita greenhouse gas emission on cities population, found negative relation with two reasons behind them. One the building and houses have very small sizes, are very close with each other and are very light and cool. These require less electric energy as compared to rural or suburban regions.

Another reason is that these towns have wide range of public transport structure which helps to lower their fuel energy as well. Al-mulali, Fereidouni, Lee, and Sab (2013) tested the relationship between urbanization, energy consumption and carbon dioxide emission in MENA countries by using panel data from the period of 1980 to 2009, results suggested that there is a significant long run affiliation exist with bi-directional causality between urbanization, energy consumption and CE. Sadorsky (2014) test the influence of urbanization on energy emission in emerging countries by using panel data of 16 countries from the period of 1971 to 2009, panel regression suggested that urbanization has a progressive and significantly impact on energy emission in 16 emerging countries. Zhang, Liu, Zhang, and Tan (2014) examined the relationship between economic growth, industrial structure and urbanization on CE in China for the period of 1978 to 2011 by using ARDL technique. Results suggested that there is long run relationship exist between urbanization and energy emission and urbanization increases energy consumption and emission significantly. 


\section{Methodology}

In accordance with the past studies, the model to investigate the impact of urbanization on carbon dioxide emission is derived by using the following framework:

$$
C E_{t}=\beta_{0}+\beta_{1} G D P_{t}+\beta_{2} P O P_{t}+\beta_{3} E N C_{t}+\beta_{4} U R B_{t}+\epsilon_{t}
$$

Where, $\epsilon_{t}$ is the error term, GDP is the gross domestic product which is measured by the final finish goods and services in the country in each year, POP is represented by population which is measured as the count of all citizens irrespective of legal status except for refugees. ENC is denoted by energy consumption which is measured as the usage of primary energy before transformation to other end use fuels. URB is the urbanization which means the peoples live in the urban society as explained by national statistical office. $\mathrm{CE}$ is the carbon dioxide emission which is measured by those stemming from the scorching of fossil fuels. The expected sign of GDP, POP and ENC are positive while, the sign of URB is to be examined. In our basic model, we ruminated GDP and POP to control the effect of both level in an economy. This study contains the yearly time series data over the era of 1972 to 2013. Entire data are collected from World Bank and several issues of economic survey of Pakistan.

\section{Unit Root Analyses}

Augmented Dickey Fuller (ADF) and Phillip Perron (PP) unit root tests are adopted to investigate the stationary importance for long-term connection of time series data.

$$
\Delta Y_{t}=\alpha_{0}+\alpha_{1} Y_{t-1}+\sum_{j=1}^{k} d_{j} \Delta Y_{t-j}+\epsilon_{t}
$$

Where $\Delta$ is first difference operator, $\epsilon_{t}$ is a pure white noise error term, $\alpha_{0}$ is a constant number in the equation, $k$ is the maximum number of lag of criterion variable and $\mathrm{Y}_{t}$ is a series of time. Dickey and Fuller (1979) test is used to investigate whether the estimations are equivalent to zero or not. This test gives the collective distribution of Augmented Dickey Fuller statistics. The variable is called stationary, if the coefficient value $\alpha_{1}$ is less than the critical values from statistics table. There is another test which estimates the same i.e. Philip Perron Unit root test. This test is calculated the coefficients of $\rho^{*}$ base on t-statistics. Phillips and Perron (1988) unit root test is based on the equation given below:

$$
\Delta Y_{t}=\alpha+\rho^{*} Y_{t-1}+\epsilon_{t}
$$

Many researches debate that these type of unit root test give ambiguous results due to their small power and size. These tests do not successfully report any evidence regarding the structural breaks restricting in the series. So, to determine the outcomes of unit root test, this study also take Zivot and Andrews (1992) structural break unit root test to investigate the breaks on structural basis in the series. 


\section{Cointegration Analyses}

This study uses two cointegration techniques, specifically autoregressive distributed lag (ARDL) cointegration and Johansen and Juselius (1990) cointegration techniques to investigate the long-term connection among urbanization and carbon dioxide emission in Pakistan. The ARDL technique of cointegration is established by Pesaran and Pesaran (1997); Pesaran and Shin (1998); Pesaran, Shin, and Smith (2000, 2001). This technique is estimated by using unrestricted VECM to analyze the long-term association between urbanization and carbon dioxide emission. The ARDL technique has numerous advantages upon other cointegration methods. The ARDL may be applied irrespective of whether underlying variables are purely I(0), I(1) or mutually co-integrated (Pesaran \& Shin, 1998). The ARDL approach has calculated enhanced small sample properties (Raza, 2015). In the ARDL method the estimates of results is even conceivable if the independent variable are endogenous (Pesaran \& Shin, 1998; Pesaran et al., 2001). The ARDL model is designed for estimations as follow:

$$
\begin{aligned}
\Delta C E_{t}=\psi_{0}+\psi_{1} \sum_{i=1}^{p} \Delta G D P_{t-1} & +\psi_{2} \sum_{i=1}^{p} \Delta P O P_{t-1}+\psi_{3} \sum_{i=1}^{p} \Delta E N C_{t-1}+\psi_{4} \sum_{i=1}^{p} \Delta U R B_{t-1} \\
& +\gamma_{1} G D P_{t-1}+\gamma_{2} P O P_{t-1}+\gamma_{3} E N C_{t-1}+\gamma_{4} U R B_{t-1}+\mu_{t}
\end{aligned}
$$

Where $\psi_{0}$ is a constant term and $\mu_{t}$ is white noise error term, the error correction dynamic are respresented by a summation sign while, the next part of the calculation links the longterm relationships. The Schwarz Bayesian Criteriona (SBC) has been taken to investigate the maximum lag of model and separate series. In ARDL approach, first we evaluate the F-statistics value by taking appropriate ARDL models. Secondly, the Wald test is taken to analyze the correlation between the series. The status of F-statistics can be accepted, rejected and inconclusive if the F-statistics are found below the lower critical bound (LCB), F-statistics are found above the upper critical bound (UCB) and F-statistics fall between the UCB and LCB respectively. If we found the long-term relationship between urbanization and carbon dioxide emission then we evaluate the long run coefficients by using following model:

$$
C E_{t}=\zeta_{0}+\zeta_{1} \sum_{i=1}^{p} G D P_{t-1}+\zeta_{2} \sum_{i=1}^{p} P O P_{t-1}+\zeta_{3} \sum_{i=1}^{p} E N C_{t-1}+\zeta_{4} \sum_{i=1}^{p} U R B_{t-1}+\mu_{t}
$$

If the long run relationship between urbanization and CE emission is found with evidence then we estimate the short run coefficients by using following model:

$$
\begin{array}{r}
\Delta C E_{t}=\varphi_{0}+\varphi_{1} \sum_{i=1}^{p} \Delta G D P_{t-1}+\varphi_{2} \sum_{i=1}^{p} \Delta P O P_{t-1}+\varphi_{3} \sum_{i=1}^{p} \Delta E N C_{t-1} \\
+\varphi_{4} \sum_{i=1}^{p} \Delta U R B_{t-1}+n E C T_{t-1}+\mu_{t}
\end{array}
$$


The error correction model (ECM) displays the shiftiness of adjustment required to collect the long-term equilibrium resulting a short run shock. The $n$ is the coefficient of error correction term in the model that specifies the shiftiness of adjustment.

The Johansen and Juselius (1990) cointegration technique is further taken to investigate the presence of long run correlation among urbanization and carbon dioxide emission. This test is constructed on $\lambda_{\text {trace }}$ and $\lambda_{\text {max }}$ indicators. First $\lambda_{\text {trace }}$ cointengration rank " $r$ " is as follow:

$$
\lambda_{\text {trace }}=-T \sum_{j=r+1}^{n} \operatorname{In}\left(1-\lambda_{j}\right)
$$

Secondly, "max test" maximum number of cointegrating vector again $r+1$ is denoted as follow:

$$
\lambda_{\max }(r, r+1)=-\operatorname{TIn}\left(1-\lambda_{j}\right)
$$

J.J cointegration has a null hypothesis that there is no long run relationship exist among the variables. If the $\left(\lambda_{\text {trace }}\right.$ and $\left.\lambda_{\max }\right)$ value is greater than critical value, then reject the null hypothesis that guides a substantial long run relationship exists among the series of variables.

In literature there are few contradictory evidence available against the ARDL and J.J cointegration approach. Many researches dispute that these cointegration techniques do not successfully give any information regarding structural breaks restricting in the series and can give ambiguous outcomes of long run relationship among the measured variables. So, to cope up the outcomes of long run relationship between urbanization and carbon dioxide emission, we also use Gregory and Hansen (1996) structural break cointegration technique to investigate the breaks on structural basis in the series.

\section{Long Run Stability and Elasticity}

This study use diverse sensitivity approach to confirm the robustness of long run relationship between urbanization and CE in Pakistan. First, by taking ARDL based coefficients technique, second, by taking fully modified ordinary least square (FMOLS) technique and finally by using dynamic ordinary least square (DOLS) technique. Also, we use a further improved technique, i.e. variance decomposition method to investigate the causal relationship between urbanization and CE. This will assist in confirming that our findings and conclusions about the causal relationship of urbanization and CE are finest, trustworthy and more consistent related to earlier work.

\section{Estimations and Results}

Augmented Dickey Fuller (ADF) and Phillip Perron (PP) unit root test are used to check the stationary properties. Table 2 explains the result of stationary test. Initially, these tests are positioned on level of variables formerly on their first difference. 
Table 2

Stationary Test Results

\begin{tabular}{|c|c|c|c|c|c|c|c|c|}
\hline \multirow[t]{3}{*}{ Variables } & \multicolumn{4}{|c|}{ Augmented Dickey-Fuller } & \multicolumn{4}{|c|}{ Phillips-Perron } \\
\hline & \multicolumn{2}{|c|}{$\mathrm{I}(0)$} & \multicolumn{2}{|c|}{$\mathrm{I}(1)$} & \multicolumn{2}{|c|}{$\mathrm{I}(0)$} & \multicolumn{2}{|c|}{$\mathrm{I}(1)$} \\
\hline & $\mathrm{C}$ & $\mathrm{C} \& \mathrm{~T}$ & $\mathrm{C}$ & $\mathrm{C} \& \mathrm{~T}$ & $\mathrm{C}$ & $\mathrm{C} \& \mathrm{~T}$ & $\mathrm{C}$ & $\mathrm{C} \& \mathrm{~T}$ \\
\hline $\mathrm{CE}$ & 1.60 & -2.56 & -4.68 & -4.87 & 1.20 & -2.50 & -4.78 & -4.92 \\
\hline GDP & -1.30 & -1.43 & -4.92 & -4.90 & -1.17 & -1.70 & -4.92 & -4.90 \\
\hline POP & -1.90 & -2.04 & -5.06 & -5.15 & -1.34 & -1.48 & -5.45 & -5.48 \\
\hline $\mathrm{ENC}$ & -1.40 & -2.75 & -4.51 & -6.10 & -1.22 & -2.75 & -4.71 & -6.10 \\
\hline URB & -1.15 & -2.12 & -5.18 & -5.27 & -0.32 & -2.84 & -5.18 & -5.30 \\
\hline
\end{tabular}

Table 2 reports that the null hypothesis of no unit root cannot be rejected at level for carbon dioxide emission $\left(C E_{t}\right)$, Gross domestic product $\left(G D P_{t}\right)$, population $\left(P O P_{t}\right)$, Energy Consumption $\left(E C_{t}\right)$ and Urbanization $\left(U R B_{t}\right)$ when they are stated in first different level, irrespective of the test used. All the variables are discovered to be stationary in their first differences. The variables in level are now suitable for the cointegration analysis.

This study also performs the Zivot and Andrews (1992) test which compensates for structural breaks. Table 3 shows that all variables found to be non-stationary in level (with intercept and trend), then stationary in their first differences. The results hence confirm those from $\mathrm{ADF}$ and $\mathrm{PP}$ unit root tests.

Table 3

Zivot-Andrews Structural Break Trended Unit Root Test

\begin{tabular}{lcccc}
\hline \multirow{2}{*}{ Variables } & \multicolumn{2}{c}{ At Level } & \multicolumn{2}{c}{ At 1st Difference } \\
& T- Statistics & Time Break & T- Statistics & Time Break \\
\hline CE & $-1.985(1)$ & 2002 & $-7.558(1)^{*}$ & 2002 \\
GDP & $-2.895(1)$ & 1992 & $-8.124(1)^{*}$ & 1993 \\
POP & $-2.029(1)$ & 2002 & $-9.005(1)^{*}$ & 2000 \\
ENC & $-1.173(1)$ & 1993 & $-5.928(1)^{*}$ & 1993 \\
URB & $-1.867(1)$ & 1997 & $-6.224(1)^{*}$ & 1996 \\
\hline Note: Lag order shown in parenthesis & & \\
* Represents significance at 1\% level & & \\
Source: Authors' estimation
\end{tabular}

The Autoregressive Distributed Lag (ARDL) technique for long run relationship can be now opted to explore the cointegration between urbanization and carbon dioxide emission, based on the outcomes of unit root tests. The initial step is to decide the optimal lag length of the variables. The order of optimal lag length is categorized by using the Schwarz Bayesian Criterion. The results of ARDL cointegration method are shown in Table 4.

Table 4

Lag Length Selection \& Bound Testing for Cointegration

\begin{tabular}{ccccc}
\hline Lags Order & AIC & HQ & sbc & F-test Statistics \\
\hline 0 & -19.407 & -19.331 & -19.196 & \\
1 & -37.003 & -36.545 & -35.736 & $49.105^{*}$ \\
2 & $-40.589^{*}$ & $-39.754^{*}$ & $-38.267^{*}$ & \\
\hline
\end{tabular}

* Represents significance at $1 \%$ level

Source: Authors' estimation 
The ARDL results propose the refusal of null hypothesis of no cointegration in model since the value of the $F$ - statistics is larger than upper bound critical value UBC at $1 \%$ level of significance in favor of alternative hypothesis that the effective long term relationship is exist between urbanization and CE in Pakistan.

Table 5

J. J. Cointegration Test

\begin{tabular}{lcccc}
\hline $\begin{array}{l}\text { Null Hypothesis } \\
\text { No. of CS(s) }\end{array}$ & $\begin{array}{c}\text { Trace } \\
\text { Statistics }\end{array}$ & $\begin{array}{c}\text { 5\% critical } \\
\text { values }\end{array}$ & $\begin{array}{c}\text { Max. Eigen } \\
\text { Value Statistics }\end{array}$ & $\begin{array}{c}\text { 5\% critical } \\
\text { values }\end{array}$ \\
\hline None & 106.177 & 79.341 & 43.928 & 37.164 \\
At most 1 & 62.249 & 55.246 & 33.034 & 30.815 \\
At most 2 & 29.215 & 35.011 & 18.590 & 24.252 \\
At most 3 & 10.626 & 18.398 & 10.459 & 17.148 \\
\hline \multicolumn{2}{l}{ Source: Authors' estimation } & & &
\end{tabular}

Johansen and Juselius (1990) cointegration method is also used to evaluate the long term relationship. Table 5 denotes the calculated and tabulated values of Trace and Maximum Eigen value statistics of Johansen and Juselius (1990) cointegration method. Outcomes specify the refusal of null hypothesis of no cointegration in model at significance level of 5 percent in favor of alternative hypothesis that is the presence of one or more cointegrating vectors. The results endorse the presence of long term relationship between urbanization and carbon dioxide emission in Pakistan.

Table 6

Gregory-Hansen Structural Break Cointegration Test

\begin{tabular}{lcc}
\hline \multicolumn{2}{c}{ ADF Procedure } \\
\hline Structural Break & \\
T-Statistics & & -498 \\
P-value & 0.000 \\
\hline \multicolumn{2}{c}{ Phillips Procedure } \\
\hline Structural Break & \\
T-Statistics & 1998 \\
P-value & -5.245 \\
\hline Source: Authors' estimation & 0.000 \\
\hline
\end{tabular}

In previous studies few researches claim that ARDL and J. J. cointegration methods provide doubtful and misleading outcomes due to existence of structural break in a series. Therefore, to determine the outcomes of long term relationship we also use Gregory and Hansen (1996) structural break cointegration approach. Table 6 signifies the results of Gregory and Hansen cointegration approach. Results again endorse the valid long run relationship between variables. Results of all three cointegration tests endorse the robustness of results that valid long run relationship exists between variables. 
Table 7

\begin{tabular}{|c|c|c|c|c|}
\hline Lag & 0 & 1 & 2 & Selected \\
\hline & SBC & SBC & SBC & Lags SBC \\
\hline CEM & 2.151 & $-4.586^{*}$ & -4.189 & 1 \\
\hline GDP & 1.874 & $-5.027^{*}$ & -4.904 & 1 \\
\hline POP & 2.144 & $-4.133^{*}$ & -3.780 & 1 \\
\hline ENC & 0.690 & -8.746 & $-11.774^{*}$ & 2 \\
\hline URB & 1.271 & -9.487 & $-11.165^{*}$ & 2 \\
\hline
\end{tabular}

After having the valid evidence of long run relationship between urbanization and carbon dioxide emission currently, we estimate the long run and short run coefficients. The lag length of all variables are identified through Schwarz Bayesian Criteria $(S B C)$. The results of lag order are presented in Table 7 . The results show that each variable should be used on lag one except energy consumption and urbanization. Both the variables should be used on lag two. Now, we estimate the long run and short run coefficients by using these lag length selection.

Table 8

Long Run Results using ARDL Approach

\begin{tabular}{lccc}
\hline Variables & \multirow{2}{*}{ Coeff. } & T-stats & Prob. \\
\hline C & -4.159 & -4.122 & 0.000 \\
GDP & 0.479 & 2.074 & 0.045 \\
POP & 0.620 & 9.060 & 0.000 \\
ENC & 0.236 & 5.613 & 0.000 \\
URB & 0.177 & 3.957 & 0.000 \\
\hline Adj. R ${ }^{2}$ & \multicolumn{3}{c}{0.968} \\
D.W stats & \multicolumn{3}{c}{1.812} \\
F-stats (Prob.) & \multicolumn{3}{c}{$26830.521(0.000)$} \\
\hline Source: Authors' estimation
\end{tabular}

Table 8 shows the results of long run estimations. Results suggest that all four variables gross domestic product, population, energy consumption and urbanization are the major significant determinants of carbon dioxide emission in Pakistan. Outcomes show the positive and significant effect of gross domestic product, population, energy consumption and urbanization on carbon dioxide emission in Pakistan. It is concluded that all the four variables are the main sources to increase the carbon emission in Pakistan. If the population is increase in the country then it will lead the urbanization because there are very few facilities available in the rural areas so the people will start moving towards the urban areas and when the urban population increases it will enhance the energy consumption in all the aspects like household consumption, electricity consumption and consumption of petroleum energy as well. In the developing countries like Pakistan, there are not enough technology to maintain the emission of carbon dioxide so, if the energy will consume from the above mention sector it will definitely enhance the carbon dioxide emission and nitrogen dioxide emission in the country. Therefore, it is concluded that gross domestic product, population, energy consumption and urbanization the four main sources to enhance the carbon dioxide emission in Pakistan. The findings of this study are consistent with the 
earlier available literature which is showing the positive relationship between urbanization and CE (Jones, 1991; York et al., 2003a, 2003b; S. Alam et al., 2007; Al-mulali et al., 2013; Sadorsky, 2014).

\begin{tabular}{lccc}
\multicolumn{3}{l}{ Table 9 } \\
Short Run Results using ARDL Approach \\
\hline Variables & Coeff. & T-stats & Prob. \\
\hline C & 0.005 & 0.367 & 0.716 \\
GDP & 0.214 & 1.985 & 0.055 \\
POP & 0.757 & 11.816 & 0.000 \\
ENC & 0.181 & 2.797 & 0.008 \\
URB & 0.099 & 2.149 & 0.039 \\
ECM(-1) & -0.392 & -4.234 & 0.000 \\
\hline Adj. R ${ }^{2}$ & \multicolumn{3}{c}{0.887} \\
D.W stats & 2.229 \\
F-stats (Prob.) & \multicolumn{3}{l}{$53.550(0.000)$} \\
\hline Source: Authors' estimation
\end{tabular}

Table 9 denotes the short run relationship between urbanization and carbon dioxide emission. Results indicate that the lagged error correction term for the estimated carbon emission model equation is both negative and statistically significant. This confirms a valid short run relationship between urbanization and carbon dioxide emission in Pakistan. The coefficient of error term is showing the value of -0.392 suggest that about $39 \%$ of disequilibrium is corrected in the current year. Table show the results that indicate the positive and significant effect of urbanization on carbon dioxide emission in Pakistan. These findings suggest that the contribution of urbanization enhance the carbon dioxide emission in Pakistan is sufficient in the short run also.

\section{Sensitivity Analysis of Long run Coefficients}

In this section to check the robustness of initial results of long run coefficients two different sensitivity analyses have been performed namely; dynamic ordinary least square $(D O L S)$ and fully modified ordinary least square (FMOLS).

Table 10

Robustness of Long run Coefficients

\begin{tabular}{lcccccc}
\hline \multirow{2}{*}{ Variables } & \multicolumn{3}{c}{ FMOLS } & \multicolumn{3}{c}{ DOLS } \\
& Coeff. & T-stats & Prob. & Coeff. & T-stats & Prob. \\
\hline C & -4.126 & -4.133 & 0.000 & -1.378 & -0.867 & 0.395 \\
GDP & 0.474 & 2.058 & 0.047 & 0.499 & 2.314 & 0.027 \\
POP & 0.639 & 9.384 & 0.000 & 0.794 & 5.890 & 0.000 \\
ENC & 0.252 & 5.824 & 0.000 & 0.229 & 2.922 & 0.008 \\
URB & 0.181 & 4.271 & 0.000 & 0.141 & 5.638 & 0.000 \\
\hline Adj. R ${ }^{2}$ & \multicolumn{3}{c}{0.982} & & & 0.961 \\
D.W stats & 1.861 & & & 2.16 & \\
\hline Source: Authors' estimation
\end{tabular}




\section{Fully Modified Ordinary Least Square (FMOLS)}

The fully modified ordinary least square technique developed by Phillips and Hansen (1990) is also used to analyze the robustness of our initial results of OLS based coefficients models. FMOLS provides the optimal estimates of the cointegration equation (Bum \& Jeon, 2006). The FMOLS modifies the $O L S$ to control the problems of serial correlation and endogeneity in the regressors that results from the existence of a cointegrating relationship (Phillips \& Hansen, 1990). Results of FMOLS of economic growth model is also presented in Table 10. Results of FMOLS endorse that the coefficients of all determinants remain same sign and significance as in the $O L S$ based coefficients model.

\section{Dynamic Ordinary Least Square}

The robustness of the relationship between dependent variable and explanatory variables is firstly tested through Dynamic Ordinary Least Square (DOLS) technique developed by Stock and Watson (1993). This method involves estimating the dependent variable on explanatory variable by using the levels, leads and lags of the explanatory variable. This method resolves the issues of small sample bias, endogeneity and serial correlation problems by adding the leads and lags of explanatory variable (Stock \& Watson, 1993).

Table 10 represents the results of dynamic ordinary least square of carbon dioxide emission model. We have run our models of DOLS by taking the lead and lag of 1 . Results endorse that the coefficients of all determinants remain same sign and significance after taking the different lag and lead in all models.

Results of both sensitivity analyses show that the coefficient of all considered variables have remain same sign and significance even magnitude is also almost same as in OLS based coefficients model. These findings confirm that the initial results are robust.

\section{Stability of Short run Model}

The stability of short run model in the sample size is evaluated by using the cumulative sum (CUSUM) and CUSUM of square test on the recursive residuals. CUSUM test detects systematic changes from the coefficients of regression, while, CUSUM of square test is able to detects the sudden changes from constancy of regression coefficients (Brown, Durbin, \& Evans, 1975). 
Figure 1: Plot of cumulative sum of recursive residuals. The straight lines represent critical bounds at $5 \%$ significance level

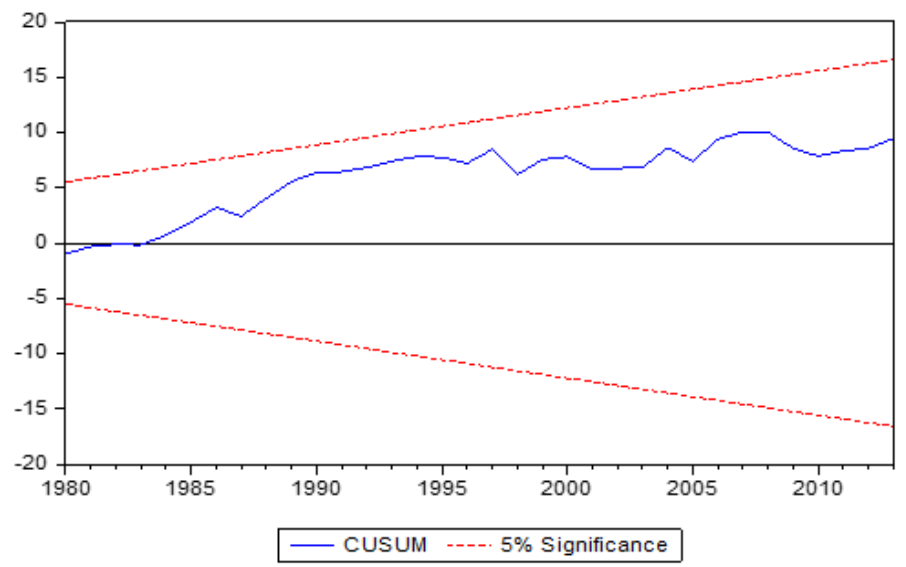

Figure 1 and 2 represents the results of CUSUM and CUSUM of square tests respectively. Results indicate that the statistics of both CUSUM and CUSUM of square test are lie within the interval bands at $5 \%$ confidence interval. Results suggest that there is no structural instability in the residuals of equation of carbon dioxide emission.

Figure 2: Plot of CUSUM of square of recursive residuals. The straight lines represent critical bounds at $5 \%$ significance level

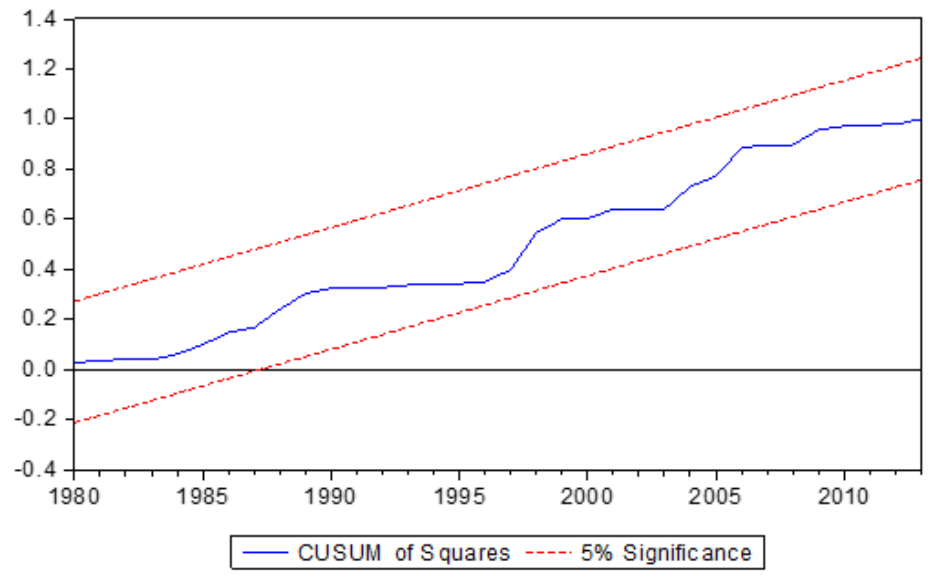

\section{Stability of Long run Model}

Another question that can emerge is whether the estimated long-run relationship is stable over time. For this purpose, we check the stability of the coefficients governing the long- 
run relationship by using the rolling window estimation method with the window size of 10 years (M. S. Alam, Raza, Shahbaz, \& Abbas, 2015; Raza, Shahbaz, \& Paramati, 2016). Figure 3 and Table 11 report the evolution of the coefficients associated with GDP, population, energy consumption and urbanization throughout the sample.

Table 11

Long run Coefficients

\begin{tabular}{lcccc}
\hline Years & GDP & ENC & POP & URB \\
\hline 1979 & -0.083 & 1.077 & 0.068 & -1.109 \\
1980 & 1.157 & 1.171 & 0.084 & -1.101 \\
1981 & 1.489 & 1.160 & 0.083 & -0.899 \\
1982 & 1.539 & 1.167 & 0.063 & -0.928 \\
1983 & 0.755 & 1.386 & 0.038 & -1.654 \\
1984 & 0.578 & 1.195 & 0.037 & -1.077 \\
1985 & 0.921 & 0.897 & 0.037 & 0.067 \\
1986 & 0.922 & 0.697 & 0.062 & 0.713 \\
1987 & 0.542 & 0.620 & 0.021 & 0.758 \\
1988 & 0.403 & 0.618 & 0.022 & 0.563 \\
1989 & 0.546 & 0.627 & 0.022 & 0.578 \\
1990 & 0.262 & 0.488 & 0.015 & 0.981 \\
1991 & 0.213 & 0.460 & 0.011 & 1.121 \\
1992 & -0.471 & 0.595 & 0.024 & 0.388 \\
1993 & -0.735 & 0.610 & 0.017 & 0.315 \\
1994 & -0.793 & 0.709 & 0.016 & 0.213 \\
1995 & -0.825 & 0.732 & 0.017 & 0.031 \\
1996 & -0.867 & 0.765 & 0.017 & -0.056 \\
1997 & 0.369 & 0.754 & 0.022 & -0.022 \\
1998 & 0.786 & 0.771 & 0.022 & 0.405 \\
1999 & 0.735 & 0.773 & 0.021 & 0.454 \\
2000 & 0.922 & 0.384 & 0.010 & 1.847 \\
2001 & 0.880 & 0.462 & 0.012 & 1.447 \\
2002 & 0.517 & 0.515 & 0.013 & 0.625 \\
2003 & 0.690 & 0.449 & 0.009 & 0.612 \\
2004 & 1.000 & 0.456 & 0.010 & 1.176 \\
2005 & 0.568 & 0.732 & 0.015 & 0.015 \\
2006 & 0.619 & 0.702 & 0.015 & -0.038 \\
2007 & 0.537 & 0.692 & 0.017 & -0.060 \\
2008 & 0.511 & 0.535 & 0.013 & 0.964 \\
2009 & 0.755 & 0.702 & 0.015 & 0.619 \\
2010 & 0.733 & 1.261 & 0.021 & -0.297 \\
2011 & 0.694 & 1.410 & 0.021 & -0.470 \\
2012 & 1.497 & 1.225 & 0.019 & 0.127 \\
2013 & -0.202 & 1.189 & 0.018 & -0.141 \\
\hline Source: Authors' & estimation & \\
& & & & \\
& & &
\end{tabular}

Results of rolling window analysis suggest that GDP majorly has the positive influence our CE. The coefficient of GDP remained positive in 28 years while negative coefficient occurred in only 7 years. Similarly, the URB also majorly has the positive influence over CE. The coefficient of URB remained positive in 22 years while, negative coefficient occurred in only 13 years. Conversely, the results of population and energy consumption suggest the positive influence over $\mathrm{CE}$ for the entire period. The coefficients of energy consumption and population remained positive for the entire period of 35 years. These findings also confirm that over selected four major determinants of $\mathrm{CE}$ are considered as a main factors to increase CE in Pakistan. 
Figure 3: Coefficient of GDP and its two S.E. bands based on rolling OLS (Dependent Variable: CE)

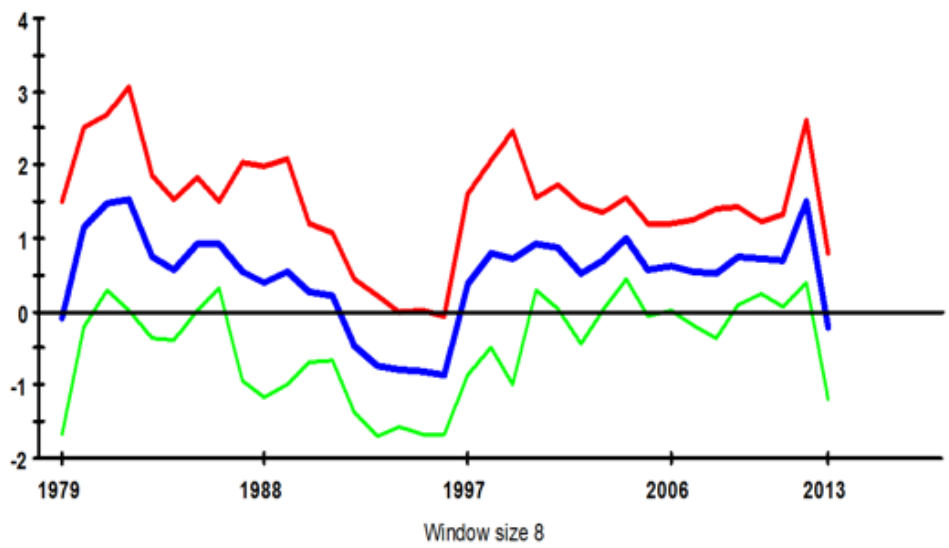

Figure 4: Coefficient of ENC and its two S.E. bands based on rolling OLS (Dependent Variable: CE)

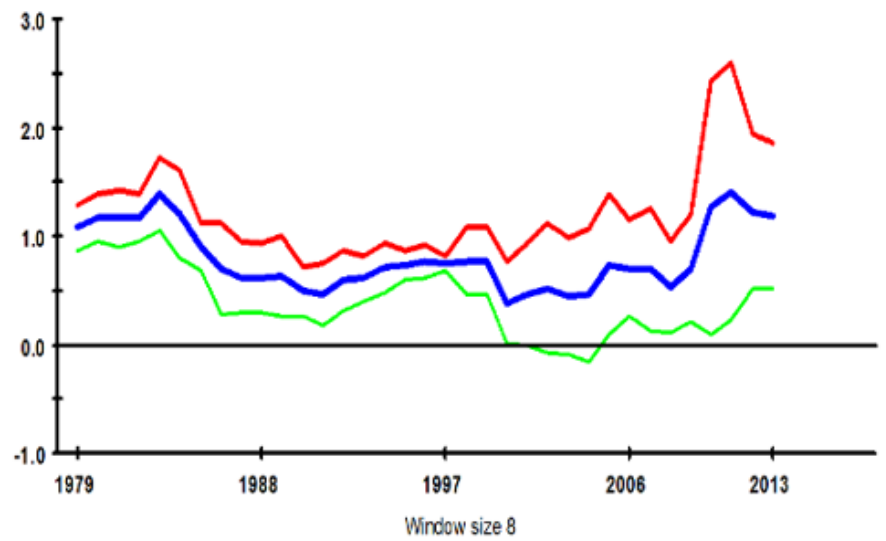


Figure 5: Coefficient of POP and its two S.E. bands based on rolling OLS (Dependent Variable: CE)

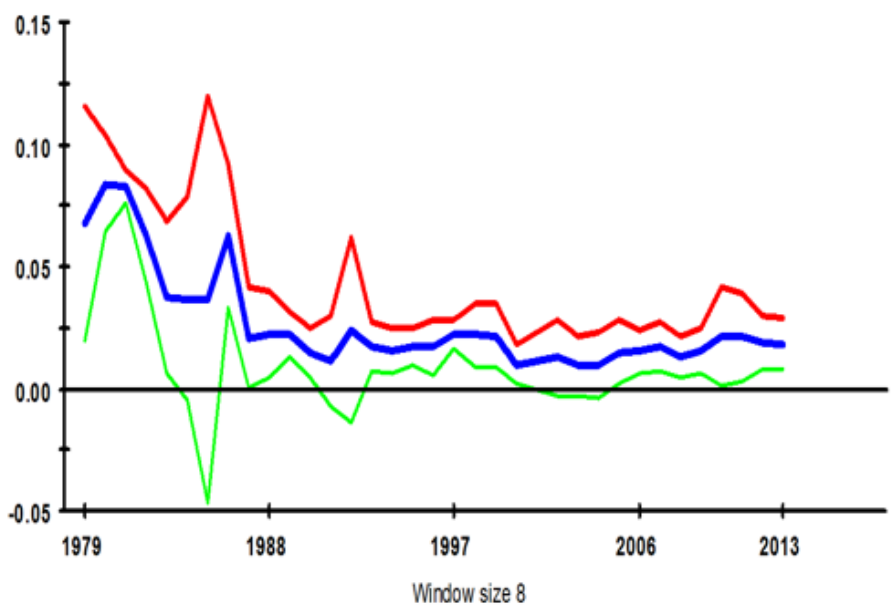

Figure 6: Coefficient of URB and its two S.E. bands based on rolling OLS (Dependent Variable: CE)

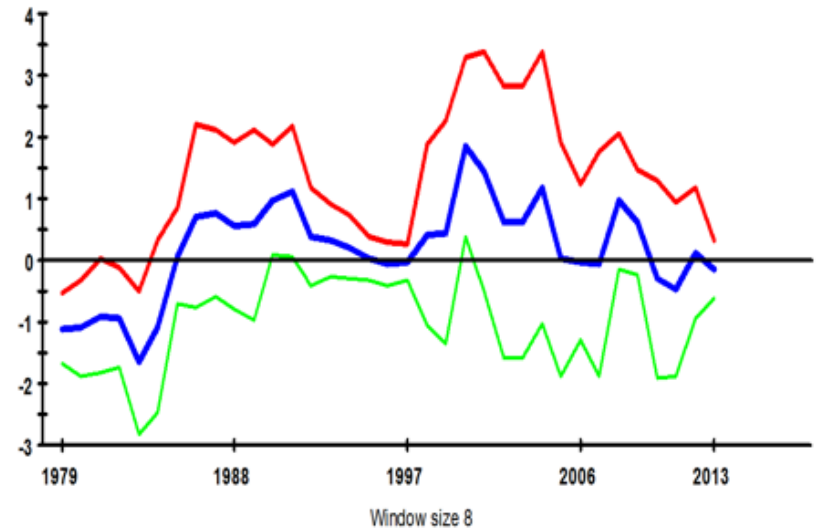

\section{Causality Analysis: Variance Decomposition Analysis}

Generalized forecast error variance decomposition method under vector autoregressive (VAR) system is used to analyze the strength of the causal relationship of urbanization and carbon dioxide emission. The variance decomposition method provides the magnitude of the predicted error variance for a series accounted for by innovations from each of the independent variable over different time period. Wong (2010); Raza, Shahbaz, and Nguyen (2015); Raza (2015) have used this approach to find causal relationship among considered variables. Table 12 represents the results of variance decomposition analysis. 
Table 12

Results of Variance Decomposition Approach

\begin{tabular}{|c|c|c|c|c|c|c|c|c|c|c|c|}
\hline Period & $\mathrm{CE}$ & GDP & ENC & POP & URB & Period & CE & GDP & ENC & POP & URB \\
\hline \multicolumn{6}{|c|}{ Variance Decomposition of CE } & \multicolumn{6}{|c|}{ Variance Decomposition of POP } \\
\hline 1 & 100.000 & 0.000 & 0.000 & 0.000 & 0.000 & 1 & 0.839 & 0.228 & 0.406 & 98.528 & 0.000 \\
\hline 2 & 83.151 & 8.105 & 7.729 & 1.002 & 0.013 & 2 & 3.419 & 1.003 & 5.272 & 90.062 & 0.245 \\
\hline 3 & 60.509 & 12.997 & 21.668 & 3.002 & 1.824 & 3 & 9.183 & 0.988 & 14.293 & 74.982 & 0.554 \\
\hline 4 & 42.250 & 16.604 & 32.249 & 6.003 & 2.893 & 4 & 14.553 & 0.685 & 24.436 & 59.690 & 0.636 \\
\hline 5 & 26.297 & 21.237 & 37.932 & 9.057 & 5.477 & 5 & 17.793 & 0.409 & 34.406 & 46.871 & 0.520 \\
\hline 6 & 11.659 & 26.226 & 40.273 & 12.318 & 9.524 & 6 & 19.122 & 0.251 & 43.090 & 37.193 & 0.344 \\
\hline 7 & 2.689 & 27.328 & 36.588 & 18.929 & 14.467 & 7 & 19.343 & 0.174 & 50.052 & 30.209 & 0.222 \\
\hline 8 & 0.108 & 23.130 & 35.447 & 21.871 & 19.443 & 8 & 19.122 & 0.167 & 55.238 & 25.281 & 0.192 \\
\hline 9 & 0.055 & 21.382 & 33.856 & 21.158 & 23.548 & 9 & 18.844 & 0.260 & 58.832 & 21.829 & 0.235 \\
\hline 10 & 0.846 & 21.252 & 33.449 & 21.097 & 23.356 & 10 & 18.681 & 0.496 & 61.104 & 19.412 & 0.308 \\
\hline \multicolumn{6}{|c|}{ Variance Decomposition of GDP } & \multicolumn{6}{|c|}{ Variance Decomposition of URB } \\
\hline 1 & 0.554 & 99.446 & 0.000 & 0.000 & 0.000 & 1 & 2.083 & 0.091 & 0.426 & 53.436 & 43.964 \\
\hline 2 & 6.397 & 87.843 & 4.594 & 0.160 & 1.005 & 2 & 2.169 & 1.059 & 1.138 & 49.446 & 46.189 \\
\hline 3 & 4.054 & 78.393 & 14.794 & 0.288 & 2.470 & 3 & 1.486 & 1.076 & 4.462 & 45.170 & 47.806 \\
\hline 4 & 3.393 & 67.687 & 21.941 & 0.391 & 6.588 & 4 & 0.870 & 0.843 & 9.064 & 40.707 & 48.515 \\
\hline 5 & 3.566 & 59.664 & 25.901 & 0.411 & 10.457 & 5 & 0.558 & 0.571 & 14.644 & 36.095 & 48.133 \\
\hline 6 & 3.810 & 51.829 & 27.434 & 0.395 & 16.532 & 6 & 0.395 & 0.405 & 20.458 & 31.744 & 46.998 \\
\hline 7 & 3.905 & 44.301 & 27.673 & 0.415 & 23.706 & 7 & 0.306 & 0.329 & 25.749 & 27.965 & 45.650 \\
\hline 8 & 3.882 & 40.667 & 27.310 & 0.506 & 27.636 & 8 & 0.320 & 0.283 & 29.898 & 24.893 & 44.607 \\
\hline 9 & 3.799 & 42.668 & 26.721 & 0.622 & 26.189 & 9 & 0.499 & 0.239 & 32.579 & 22.484 & 44.199 \\
\hline 10 & 3.707 & 44.807 & 26.048 & 0.692 & 24.745 & 10 & 0.895 & 0.217 & 33.727 & 20.595 & 44.566 \\
\hline \multicolumn{12}{|c|}{ Variance Decomposition of ENC } \\
\hline 1 & 77.221 & 2.821 & 19.958 & 0.000 & 0.000 & & & & & & \\
\hline 2 & 64.350 & 7.668 & 26.465 & 1.068 & 0.450 & & & & & & \\
\hline 3 & 47.542 & 10.151 & 38.490 & 2.096 & 1.721 & & & & & & \\
\hline 4 & 39.518 & 14.496 & 37.878 & 4.094 & 4.014 & & & & & & \\
\hline 5 & 35.439 & 18.503 & 31.783 & 8.104 & 6.171 & & & & & & \\
\hline 6 & 33.472 & 22.700 & 23.014 & 13.292 & 7.522 & & & & & & \\
\hline 7 & 32.465 & 23.046 & 16.869 & 19.795 & 7.825 & & & & & & \\
\hline 8 & 32.104 & 22.719 & 12.077 & 25.574 & 7.526 & & & & & & \\
\hline 9 & 32.194 & 21.887 & 14.347 & 24.454 & 7.118 & & & & & & \\
\hline 10 & 32.461 & 20.329 & 17.166 & 23.250 & 6.793 & & & & & & \\
\hline
\end{tabular}

The results of Table 12 shows the causal relationship of urbanization with carbon emission. The results of carbon dioxide emission model suggest that in initial round, the change in carbon dioxide emission is explained $100 \%$ entirely by its own improvements. In the second period $83.151 \%$ describe by own improvement, $8.105 \%$ by GDP, $7.729 \%$ by energy consumption, $1.002 \%$ by population and $0.013 \%$ by urbanization. In period five the shocks in carbon dioxide emission describe $26.297 \%$ by its own improvement, $21.237 \%$ by GDP, $37.932 \%$ by energy consumption, $9.057 \%$ by population and $5.477 \%$ by urbanization. In tenth period the shocks of carbon dioxide describe $0.846 \%$ by its own, $21.252 \%$ by GDP, $33.449 \%$ by energy consumption, $21.097 \%$ by population and $25.356 \%$ by urbanization, respectively. Whereas, in reverse the causal relationship at tenth level, the shocks of urbanization describe $44.566 \%$ by its own, $0.217 \%$ by GDP, $33.727 \%$ by energy consumption, $20.595 \%$ by population and $0.895 \%$ by carbon dioxide emission. These findings propose the uni-directional causal relationship of urbanization in Pakistan which runs from urbanization to carbon dioxide emission. 


\section{Conclusion and Policy Implications}

This study identifies the relationship among urbanization and carbon dioxide emission in Pakistan by taking annual time series data from the period of 1972 to 2013. Present study use number of persons live in city areas in order to find out the impact of urbanization on carbon dioxide emission in Pakistan. The ARDL bound testing cointegration approach, Johansen and Juselius cointegration approach and finally Gregory Hansen structural break cointegration approach endorse the valid the long run relationship among urbanization and carbon dioxide emission. The outcomes of ARDL based coefficient model, fully modified ordinary least square method and dynamic ordinary least square technique specify that urbanization have positive and significant impact on carbon dioxide emission in long run. The same positive and significant relationship is found in the short run as well. The consequence of causality analysis by using variance decomposition approach recommend the unidirectional causal relationship of urbanization and carbon dioxide emission in Pakistan which runs from urbanization to carbon dioxide emission.

Clearly, the past studies appear to propose that urbanization is a contributing factor to the levels of carbon dioxide emissions. Therefore, there is need of some realistic policies should be adopted to encourage the low-carbon consuming activities of urban citizens and contain luxury consumption of energy-intensive products. So, the government has to develop systematic development for urban expansion. For example, the should allocate greater portion to environmental safeguard and energy saving components in the planning, such as cheering energy saving framework and creating a chains of increasing indicators of environmental protection and energy saving. Similarly, government has to equal the growth or urbanization and population to avoid environment damage and pollution causing from overpopulation afar environment capacity. Along with this, it is essential to bring out the improvement in household registration system from welfare system which includes pension system, medical insurance and education right etc. Moreover, government should develop policies to reduce the restrictions and barrier about labor migration in the progression of urbanization and thus recognizing the balanced assignment of labor force in both rural and urban areas.

Furthermore, the government has the concern to enhance lower-carbon emission consumption pattern in the public and create it incorporated with each linkage of household and production living. Along with this the government has the concern to implement efficient methods to assist peoples (mainly the youngster) to promote environmental friend and energy saving habits and use more low-carbon products. 


\section{References}

Alam, M. S., Raza, S. A., Shahbaz, M., \& Abbas, Q. (2015). Accounting for contribution of trade openness and foreign direct investment in life expectancy: The long-run and short-run analysis in pakistan. Social Indicators Research, 1-16. doi: 10.1007/ s11205-015-1154-8

Alam, S., Fatima, A., \& Butt, M. S. (2007). Sustainable development in Pakistan in the context of energy consumption demand and environmental degradation. Journal of Asian Economics, 18(5), 825-837.

Al-mulali, U., Fereidouni, H. G., Lee, J. Y., \& Sab, C. N. B. C. (2013). Exploring the relationship between urbanization, energy consumption, and CO 2 emission in MENA countries. Renewable and Sustainable Energy Reviews, 23, 107-112.

Brown, R. L., Durbin, J., \& Evans, J. M. (1975). Techniques for testing the constancy of regression relationships over time. Journal of the Royal Statistical Society. Series B (Methodological), 37(2), 149-192.

Bum, C., \& Jeon. (2006). Demographic change and economic growth: An inverted-U shape relationship. Economics Letters, 92(3), 447-454.

Chen, H., Jia, B., \& Lau, S. (2008). Sustainable urban form for Chinese compact cities: Challenges of a rapid urbanized economy. Habitat International, 32(1), 28-40.

Cole, M. A., \& Neumayer, E. (2004). Examining the impact of demographic factors on air pollution. Population and Environment, 26(1), 5-21.

Dhakal, S., Kaneko, S., \& Imura, H. (2002). An analysis on driving factors for CO2 emissions from energy use in Tokyo and Seoul by factor decomposition method. Environmental Systems Research, 30(11), 295-303.

Dickey, D. A., \& Fuller, W. A. (1979). Distribution of the estimators for autoregressive time series with a unit root. Journal of the American statistical association, 74 (366a), $427-431$.

Dodman, D. (2009). Blaming cities for climate change? An analysis of urban greenhouse gas emissions inventories. Environment and Urbanization, 21(1), 185-201.

Ehrhardt-Martinez, K., Crenshaw, E. M., \& Jenkins, J. C. (2002). Deforestation and the Environmental Kuznets Curve: A Cross-National Investigation of Intervening Mechanisms. Social Science Quarterly, 83(1), 226-243.

Gregory, A. W., \& Hansen, B. E. (1996). Practitioners corner: tests for cointegration in models with regime and trend shifts. Oxford bulletin of Economics and Statistics, $58(3), 555-560$.

Holtedahl, P., \& Joutz, F. L. (2004). Residential electricity demand in Taiwan. Energy economics, 26(2), 201-224.

International Energy Agency. (2008). World Energy Outlook 2008. IEA, Paris.

Johansen, S., \& Juselius, K. (1990). Maximum likelihood estimation and inference on cointegration with applications to the demand for money. Oxford Bulletin of Economics and statistics, 52(2), 169-210.

Jones, D. W. (1991). How urbanization affects energy-use in developing countries. Energy Policy, 19(7), 621-630. 
Liddle, B. (2004). Demographic dynamics and per capita environmental impact: Using panel regressions and household decompositions to examine population and transport. Population and Environment, 26(1), 23-39.

Liu, Y. (2009). Exploring the relationship between urbanization and energy consumption in China using ARDL (autoregressive distributed lag) and FDM (factor decomposition model). Energy, 34(11), 1846-1854.

MacKellar, F. L., Lutz, W., Prinz, C., \& Goujon, A. (1995). Population, households, and CO2 emissions. Population and Development Review, 21 (4), 849-865.

Mishra, V., Smyth, R., \& Sharma, S. (2009). The energy-GDP nexus: evidence from a panel of Pacific Island countries. Resource and Energy Economics, 31 (3), 210-220.

Newman, P. G., \& Kenworthy, J. R. (1989). Cities and automobile dependence: An international sourcebook. Gower Publishing.

Pachauri, S. (2004). An analysis of cross-sectional variations in total household energy requirements in India using micro survey data. Energy policy, 32(15), 1723-1735.

Pachauri, S., \& Jiang, L. (2008). The household energy transition in India and China. Energy policy, 36(11), 4022-4035.

Parikh, J., \& Shukla, V. (1995). Urbanization, energy use and greenhouse effects in economic development: Results from a cross-national study of developing countries. Global Environmental Change, 5(2), 87-103.

Pesaran, M. H., \& Pesaran, B. (1997). Working with microfit 4.0: interactive econometric analysis; [windows version]. Oxford University Press.

Pesaran, M. H., \& Shin, Y. (1998). An autoregressive distributed-lag modelling approach to cointegration analysis. Econometric Society Monographs, 31, 371-413.

Pesaran, M. H., Shin, Y., \& Smith, R. J. (2000). Structural analysis of vector error correction models with exogenous I (1) variables. Journal of Econometrics, 97(2), 293-343.

Pesaran, M. H., Shin, Y., \& Smith, R. J. (2001). Bounds testing approaches to the analysis of level relationships. Journal of applied econometrics, 16 (3), 289-326.

Phillips, P. C., \& Hansen, B. E. (1990). Statistical inference in instrumental variables regression with I (1) processes. The Review of Economic Studies, 57(1), 99-125.

Phillips, P. C., \& Perron, P. (1988). Testing for a unit root in time series regression. Biometrika, 75(2), 335-346.

Raza, S. A. (2015). Foreign direct investment, workers' remittances and private saving in Pakistan: an ARDL bound testing approach. Journal of Business Economics and Management, 16(6), 1216-1234.

Raza, S. A., Shahbaz, M., \& Nguyen, D. K. (2015). Energy conservation policies, growth and trade performance: Evidence of feedback hypothesis in Pakistan. Energy Policy, $80,1-10$.

Raza, S. A., Shahbaz, M., \& Paramati, S. R. (2016). Dynamics of Military Expenditure and income Inequality in Pakistan. Social Indicators Research, 1-21. doi: 10.1007/ s11205-016-1284-7

Sadorsky, P. (2014). The effect of urbanization on CO 2 emissions in emerging economies. Energy Economics, 41, 147-153. 
Shi, A. (2003). The impact of population pressure on global carbon dioxide emissions, 1975-1996: evidence from pooled cross-country data. Ecological Economics, 44(1), $29-42$.

Stock, J. H., \& Watson, M. W. (1993). A simple estimator of cointegrating vectors in higher order integrated systems. Econometrica: Journal of the Econometric Society, 62(4), 783-820.

United Nations. (2008). World urbanization prospects: The 2007 revision. New York, United Nations, Departmanet.

Wong, H. T. (2010). Terms of trade and economic growth in Japan and Korea: an empirical analysis. Empirical Economics, 38(1), 139-158.

York, R. (2007). Demographic trends and energy consumption in European Union Nations, 1960-2025. Social science research, 36(3), 855-872.

York, R., Rosa, E. A., \& Dietz, T. (2003a). Footprints on the earth: The environmental consequences of modernity. American sociological review, 68(2), 279-300.

York, R., Rosa, E. A., \& Dietz, T. (2003b). STIRPAT, IPAT and ImPACT: Analytic tools for unpacking the driving forces of environmental impacts. Ecological economics, 46(3), 351-365.

Zhang, Y.-J., Liu, Z., Zhang, H., \& Tan, T.-D. (2014). The impact of economic growth, industrial structure and urbanization on carbon emission intensity in China. Natural hazards, $73(2), 579-595$.

Zivot, E., \& Andrews, D. (1992). Further evidence on the great crash, the oil-price shock, and the unit-root hypothesis. Journal of Business \&5 Economic Statistics, 10(3), $251-270$. 